\title{
ASPECTOS SOBRE A AFETIVIDADE E O PROCESSO DE ENSINO E APRENDIZAGEM: PERSPECTIVAS PARA O ESPAÇO ESCOLAR
}

\author{
Marcela Corrêa Tinti \\ Universidade Estadual Paulista - UNESP, Presidente Prudente, SP. E-mail: marcellatinti@gmail.com
}

\begin{abstract}
RESUMO
Com o intuito de colaborar com os processos de escolarização, a presente pesquisa tem como objetivo geral analisar os aspectos objetivos e subjetivos relacionados à afetividade no processo de ensino e de aprendizagem escolar. Para isso, a partir de uma pesquisa do tipo bibliográfica foram analisados 30 artigos em que buscou-se perceber as nuances que compõem a temática do estudo por meio de leitura descritiva de artigos, teses e dissertações. As reflexões a respeito do processo de composição das práticas escolares compõem o referencial do estudo que perpassa a concepção da afetividade no espaço escolar, a patologização do ensino e a importância das relações interpessoais na aprendizagem. A partir da compreensão de cada temática, compreendemos que o espaço educacional precisa superar perspectivas padronizadas e o estigma do diagnóstico a fim de proporcionar por meio de práticas escolares o desenvolvimento da aprendizagem.
\end{abstract}

Palavras-Chave: Afetividade no espaço escolar; patologização do ensino; relações interpessoais para a aprendizagem.

\section{ASPECTS ON THE AFFECTIVENESS AND TEACHING AND LEARNING PROCESS: PERSPECTIVES FOR A SCHOOL SPACE}

\begin{abstract}
With the purpose for collaborating with school processes, the present research has as general objective analyze aspects related to the affectivity in the process of teaching and learning in school, as well as the relations between the students and teachers. For this, from a bibliographic research, 30 articles were analyzed which it was sought to understand the nuances that make up the study theme through a descriptive reading of articles, theses and dissertations. The reflections about the process of composition of the school practices make up the reference of the study that perpasses the conception of the affectivity in the school space, the pathologization of the teaching and the importance of the interpersonal relations in the learning. From the understanding of each subject, we understand that the educational space needs to overcome standardized perspectives and stigma of the diagnosis in order to provide through school practices the development of learning.
\end{abstract}

Keywords: Affectivity in school space; Pathologization of teaching; Interpersonal relationships for learning. 


\section{INTRODUÇÃO}

Refletir a respeito da afetividade e estabelecer relações com o desenvolvimento da aprendizagem de uma criança é considerar que a afetividade se configura como temática importante e constantemente presente na vivência de qualquer ser humano. Apesar de encontrarmos resistência, ou desconhecimento a respeito do que se caracteriza a afetividade no espaço escolar, o afeto e as relações estabelecidas a partir desse conceito acontecem independentes da origem, gênero ou classe social.

Dentro das prerrogativas do que compreende o espaço escolar, Alves (2003) corrobora que a escola ensina o nome das coisas e não o que as coisas são, e que o ensinar geralmente é contido as ações faladas com expressões vazias e com conteúdo sem sentido. Tais afirmações nos fazem refletir sobre o que compreende ensinar, o que favorece o aprender e como elencar no espaço escolar o desenvolvimento pleno do estudante.

Estudos como o de Silva (2013) indicam que o tema "afetividade na aprendizagem" tem sido muito explorado e revelam uma propositura de transformação, sobretudo diante a tentativa de romper com a perspectiva teórica tradicional para o reconhecimento de propostas diversificadas que acometem desde o movimento escolanovista, aos estudos de Jean Piaget, Paulo Freire, Magda Soares, Emília Ferreiro, entre outros. Mas, segundo a autora, mesmo diante ao movimento de pesquisas que convergem com a necessidade de se pensar o ensino e a aprendizagem de maneira diversificada, percebemos na atualidade que a escola ainda está enraizada em práticas que distanciam, e muitas vezes, desestimulam a fluidez do raciocínio e das emoções, e consequentemente, a aprendizagem.

Para Freire (2001) aprendizagem corresponde a um processo de significado, imerso no contexto para resignificar o mundo. Para Wallon (1968) o indivíduo é corpóreo, o que significa que precisa ser compreendido em sua concretude, seus domínios cognitivos, afetivos e motor. Vygotsky (1987) enfatiza que aprender transcende as interações internas elencando a externas, colocando o ser humano em um processo de aprendizagem constante, de trocas intensas, de construção socialmente partilhada mediada pelas emoções e percepções do meio.

Considerando as especificidades de cada autor, entendemos que o ser humano precisa ser percebido de maneira global. Para isso, temos por objetivo neste artigo refletir sobre as particularidades e contribuições da afetividade para o processo de ensino e de aprendizagem escolar, analisando aspectos, objetivos e subjetivos, relacionados à afetividade no processo de ensino e de aprendizagem escolar.

\section{METODOLOGIA}

A metodologia da pesquisa compõe os caminhos e escolhas que o pesquisador tomou no decorrer dos estudos. Corresponde ao tracejar das condutas e ações realizadas para o desenvolvimento e análise dos resultados da pesquisa. Por isso, para a propositura desta pesquisa, nos pautamos nos indícios da pesquisa bibliográfica. Esse tipo de pesquisa condiz com uma revisão criteriosa da literatura, a partir de análise crítica e meticulosa das áreas temáticas que enredam o objeto do estudo e que subsidiam as publicações atuais da área da pesquisa. (LAKATOS; MARCONI, 2004).

A pesquisa bibliográfica tem por principio clarificar e discutir um tema específico, tendo por base referencial teórico publicado em diversas fontes como livros, periódicos, revistas, anais de eventos, assim como também, pesquisas e nível de especialização, mestrados e doutorados, disponibilizados em base de dado. É um tipo de pesquisa que, apresenta como finalidade, colocar o pesquisador e contato direto com um assunto específico a partir de tudo o que foi escrito, dito ou filmado. (LAKATOS; MARCONI, 2004).

Essas características colocam a pesquisa do tipo bibliográfica como uma possibilidade de exame profundo sobre um determinado assunto, a partir da perspectiva de uma nova abordagem, 
a fim de se proporcionar considerações inovadoras. A essas ideias Demo (2000) acrescenta que as pesquisas do tipo bibliográfico proporcionam conhecimento das temáticas e eixos de pesquisa atual, e também autoconhecimento do pesquisador diante ao problema de pesquisa e objeto a ser estudado.

Para o desenvolvimento deste estudo privilegiamos as pesquisas com temáticas que apresentassem os descritores "afetividade no espaço escolar" "patologização do ensino" e "relações interpessoais na aprendizagem". Além dos descritores, buscou-se compreender as particularidades do espaço escolar, a partir dos estudos que contemplam propostas para a composição da prática pedagógica. Com isso, a pesquisa bibliográfica proporcionaram uma ação reflexiva e crítica sobre o material de pesquisa já produzido, como descreve Gil (2004).

\section{RESULTADOS}

A composição dos estudos atentou-se a busca de base de dados tendo como pressuposto principal o Literatura Latino Americano e do Caribe em Ciências Sociais e da Saúde (LILACS), o Scientific Eletronic Library OnLine (Scielo) e Banco de Teses e Dissertações da Capes. Os artigos foram selecionados a partir dos principais descritores: "afetividade no espaço escolar" "patologização do ensino" e "relações interpessoais na aprendizagem".

Os artigos foram selecionados a partir da variável de interesse, respeitando a temática e o objeto de pesquisa, e totalizaram 30 artigos. O processo de seleção aconteceu, tendo por base, leitura criteriosa dos artigos, teses e dissertações localizadas nas bases de dados. Foram incluídas e analisadas apenas as publicações que atendiam ao objetivo da pesquisa, e que correspondiam ao delineamento teórico e epistemológico do estudo.

Mediante a sistematização das informações encontradas, a análise dos dados aconteceu a partir da leitura integral de todo o material selecionado, tendo como aspectos orientadores síntese e fichamento. Dessa maneira, buscou-se compreender e ampliar o conhecimento sobre a temática de estudo para estabelecer articulação entre proposta teórica e pesquisas estudadas para inferir novas perspectivas.

\section{DISCUSSÃO}

Para Wallon (1968) a dimensão afetiva é o ponto central do ser humano, diferenciando-se da emoção e configura-se como um estado psicológico que pode ser influenciado ou modificado por meio de situações externas. Isso significa que, é um estado influenciador do comportamento humano, o que pode abarcar áreas como a aprendizagem e o desenvolvimento cognitivo.

Por se configurar como um estado e não uma emoção, a afetividade aparece nos sentimentos, desejos, interesses, valores e emoções, contemplando a vida do ser humano por completo.

Com isso, a afetividade está instrisicamente relacionada à emoção, influenciando diretamente a maneira que cada ser humano visualiza e interage com o mundo. Como uma rede, os acontecimentos da vida de uma pessoa rememoram fatos e experiências, memórias que estabelecem relação de afeto e que indicam como a afetividade influenciou ou determinou o desenvolvimento do individuo.

A autoestima, ainda de acordo com os pressupostos de Wallon (1968), está tem relação direta com os estímulos e relações estabelecidas desde a primeira infância, por isso está intimamente ligada à afetividade. Para o autor, a partir da afetividade a criança consegue desenvolver-se com segurança e determinação, e em cada estágio o desenvolvimento da criança acontece de maneira que os momentos preeminentemente afetivos sejam sucedidos por momentos cognitivos.

A determinação dos estágios para Wallon (1968) geralmente acomete períodos estabelecidos por meio afetivo e cognitivo, enquanto os estágios afetivos acontecem em períodos 
centrados na construção interior e subjetiva do "eu", e os estágios com proeminência cognitiva centram-se à construção do real para a compreensão do mundo físico.

Este movimento cíclico nunca é finalizado e acontece durante toda a vida do ser humano, uma vez que as emoções e razões incomodam o individuo frente ao desconhecido. Com esse movimento, os aspectos de afetividade e cognição estão em movimento constante e revezam na dominância dos estágios.

Em cada estágio da afetividade, as emoções implicam o desenvolvimento de capacidades cognitivas, e estas aparecem de acordo com a expectativa do desenvolvimento biológico por ações interligadas. Isto significa que, quanto mais habilidade se adquire no campo da racionalidade, maior é o desenvolvimento da afetividade.

Com isso a aprendizagem acontece na associação desses conceitos, implicando sempre na passagem por um novo estágio. Estas relações de aprendizagem têm para Wallon (1968) base inicial no âmbito familiar e depois, no social, que compreende a escola, tornando a aprendizagem um processo dialético de desenvolvimento sem fim.

A partir dos pressupostos do autor, a aprendizagem configura-se como um processo interno e subjetivo, único e particular. Cada ser humano desenvolverá a partir das relações, estímulos, e afetividade que estabeleceu no meio, o que a luz da teoria walloniana torna o aprender um processo singular.

Wallon (1968) caracteriza o desenvolvimento humano em cinco etapas: impulsivoemocional; sensório-motor e projetivo; personalismo; categorial; e puberdade e adolescência. É no decorrer do processo evolutivo, que compreende a capacidade biológica do individuo, que a afetividade e a inteligência se configuram.

Dessa maneira, o afeto aclara a formação das estruturas motora, afetiva e cognitiva do ser humano e torna-se impensável para a concepção de qualquer espaço que tenha por premissa o aprender. A partir desses preceitos é possível favorecer ou desestimular o desenvolvimento intelectual da criança, tendo por eixo motriz a afetividade.

Tais indicativos tem ação diretamente proporcional ao processo de ensino e de aprendizagem e são faces que interligam a relação professor e estudante. Nessas relações a afetividade pode ser determinante no desenvolvimento das ações cognitivas do estudante para o sucesso, fracasso, estímulo, pertencimento, segurança, confiança e autoestima.

O processo de ensino ainda corresponde, a partir dessas premissas, como condição social que marcará o ser humano nas relações que estabelece. A partir de uma perspectiva afetiva, percebida a partir da postura do professor, pode ser ofertado uma variedade de situações, para que todos os estudantes participem igualmente e respondam às indagações realizadas para intencionar explorar o mundo e favorecer para o estudante o processo de autoconhecimento e diferenciação dos objetos.

O espaço não é primitivamente uma ordem entre as coisas, é antes uma qualidade das coisas em relação a nós próprios, e nessa relação é grande o papel da afetividade, da pertença, do aproximar ou do evitar, da proximidade ou do afastamento. (WALLON, 1986, p.33).

Com isso, o autor indica que a afetividade constitui o desenvolvimento do ser humano, por meio de movimentos, atitudes, ações, circunstâncias, atos motores ou cognitivos. No conviver permitimos a aproximação ou o retraimento liberando reações assim como também sensações de bem ou mal-estar. É nesse viés que se centra o ensino e a aprendizagem, refletindo estreitamente desde a composição e organização espacial do espaço escolar até como são incitados sentimentos, como alegria, serenidade ou tristeza.

Para isso, o espaço escolar e o processo de ensino precisam ofertar a possibilidade de escolha, pertença e bem estar. O método precisa corresponder às necessidades dos estudantes, e 
favorecer o conhecimento de e para a vida evitando julgamentos equivocados, para perceber o estado emocional.

Contudo é importante ressaltar que a afetividade corresponde ao respeito e reconhecimento das diferenças, e em como tais despontam na caracterização de cada indivíduo. Por isso, a afetividade é concebida por meio da vivência, a partir da aproximação física, da interação estabelecida nas semelhanças e diferenças, por meio da comunicação, comportamentos, intenções, crenças, valores, sentimentos e desejos.

Temos que a afetividade é compreender e intuir o indivíduo como um ser motor, afetivo e cognitivo, com ações interligadas entre o pensar e sentir, em que a afetividade integra o processo de construção do conhecimento e implica para a prática pedagógica a necessidade de ultrapassar a dimensão cognitiva.

A partir desses preceitos, a necessidade de refletir sobre a maneira de ensinar é tão importante quanto o conteúdo a ser ensinado. É nesse contexto que a intensidade das relações, assim como os aspectos emocionais, a dinâmica das manifestações e as formas de comunicação assumem preceitos indispensáveis ao processo de construção do conhecimento. Inerentemente relacionada à cognição, a afetividade compõe condição indissociável para a vida escolar, delimitando o campo de atuação profissional, e clarificando as maneiras que a criança desenvolvese e aprende.

De acordo com autores como Vygostsky (1987), Wallon (1968) e Freire (2001) a aprendizagem é um processo que acontece mediante o desenvolvimento cognitivo, afetivo, linguagem e interações sociais. Nesse viés, temos que as relações interpessoais configuram parte importante das relações humanas, e podem ser compreendidas como relações públicas, relações comunitárias, etc. As relações humanas ocorrem mediante as interações entre os indivíduos em diversos espaços e aspectos.

E nos espaços educacionais a representação docente tem papel fundamental nas relações de aprendizagem. Nesse processo o professor está diretamente relacionado às relações interpessoais e pode representar e proporcionar vínculo favorável ou desfavorável para desenvolvimento das práticas escolares.

\section{CONCLUSÃO}

Nesse contexto percebemos que, apesar da complexidade humana e de características específicas que compõem as expectativas educacionais na sociedade atual, que pensar em um ambiente escolar qualitativo pressupõe refletir a respeito dos conceitos que fomentam as relações humanas e as práticas escolares. Isso significa transpor o olhar para além da padronização que enreda as expectativas de aprendizagem dos estudantes para a perspectiva de uma percepção profunda das reais possibilidades que cada ser humano pode ter.

Essa concepção modifica os conceitos diretivos para a proposta do ensino e concebem o aprender como um ato construtivo. Nesse contexto, as relações interpessoais, a composição de um espaço afetuoso, a prática pedagógica e a percepção das características dos estudantes possibilitarão o aprender. Isso nos indica que um diagnóstico não é a culpabilização da não aprendizagem de um estudante, mas a característica que nos indica caminhos e estratégias para a conduta, encaminhamentos e construções que serão propostas.

\section{REFERÊNCIAS}

ALVES, R. Conversas sobre educação. Campinas, SP: Verus Editora, 2003.

BRUST, J. R. A influência da afetividade no processo de aprendizagem de crianças nos anos iniciais do ensino fundamental. Monografia. Universidade Estadual de Londrina. 2009. 
COLLARES, C. A. L; MOYSÉS, M. A. A. A transformação do espaço pedagógico em espaço clínico (a patologização da educação). Série Ideias, São Paulo, n. 23, p. 25-31, 1994.

DAMKE, I. R. O processo do conhecimento na pedagogia da libertação: as ideias de Freire, Fiori e Dussel. Petrópolis: Vozes, 1995.

DEMO, P. Pesquisa: princípios científicos e educativos. 7 ed. São Paulo: Cortez, 2000

FREIRE, P. Quando as ideias e os afetos se cruzam. Recife: Editora Universitária da UFPE, 2001. 242 p.

GIL, A. C. Como elaborar projetos de pesquisa. 5ed. São Paulo: atlas, 2004.

HABERMAS, J. Entre naturalismo e religião. Estudos filosóficos. Tradução Flávio Beno Siebeneichler. Rio de janeiro: Tempo Brasileiro, 2005.

LAKATOS, E. M.; MARCONI, M. A.. Metodologia científica. 4. ed. São Paulo: Atlas, 2004.

LEONTIEV, A.(1978). O desenvolvimento do psiquismo (3a ed.). Lisboa: Livros Horizonte MANTOAN, M.T.E. O direito à diferença nas escolas. Revista pátio. 2004.

MOYSÉS, M. A. A. (2001). A institucionalização invisível - crianças que não-aprendem-na-escola. Campinas, SP: FAPESP/ Mercado de Letras.

MINUCUCCI, A. - Relações Humanas: psicologia das relações interpessoais. São Paulo, Atlas 1978.

SCHLÜNZEN, E.T.M. Mudanças nas práticas pedagógicas do professor: criando um ambiente construcionista contextualizado e significativo para crianças com necessidades especiais físicas. São Paulo: Tese de Doutorado, PUC/SP, 2000.

SCHLÜNZEN, E.T.M. Abordagem Construcionista, Contextualizada e Significativa: formação, extensão e pesquisa em uma perspectiva inclusiva. Tese (Livre Docência). Universidade Estadual Paulista, Presidente Prudente, São Paulo. 2015.

SILVA, N. A. A importância da afetividade na relação professor - aluno. Monografia. Universidade Estadual do Rio de Janeiro. 2013.

VALENTE, J. A. Espiral da aprendizagem e as tecnologias da informação e comunicação: repensando conceitos. In: JOLY, M. C. R. A. Tecnologia no ensino: implicações para a aprendizagem. São Paulo. Casa do Psicólogo, 2002. P.15-37.

VYGOTSKY, L. S. Pensamento e Linguagem. São Paulo: Martins Fontes, 1987.

WALLON, H. Do ato ao pensamento: ensaio de psicologia comparada. Petrópolis: Vozes, 2008.

WELCH, G, SCHWARTZ, L, WOLOSHIN, S. (2008). O que está nos deixando doentes é uma epidemia de diagnósticos. Jornal do Cremesp, p. 12, fev. 